\title{
Small Inertial Fusion Energy (IFE) Demonstration Reactors
}

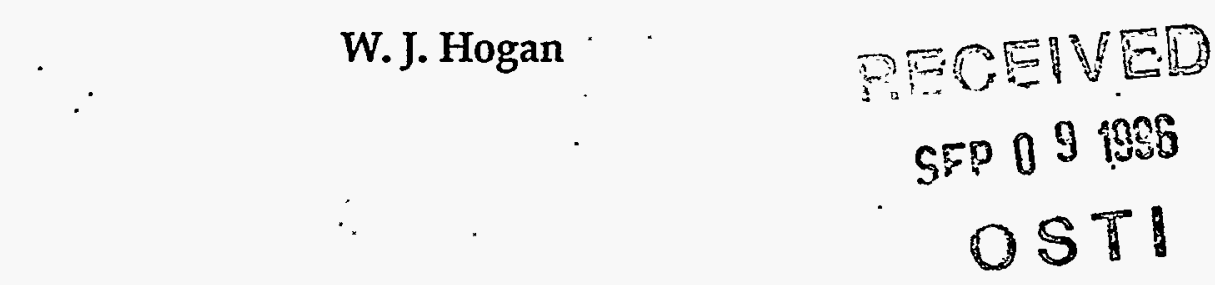

This paper was prepared for submittal to the

IEEE 14th Symposium

San Diego, CA

September 30-October 3, 1991

October 3, 1991

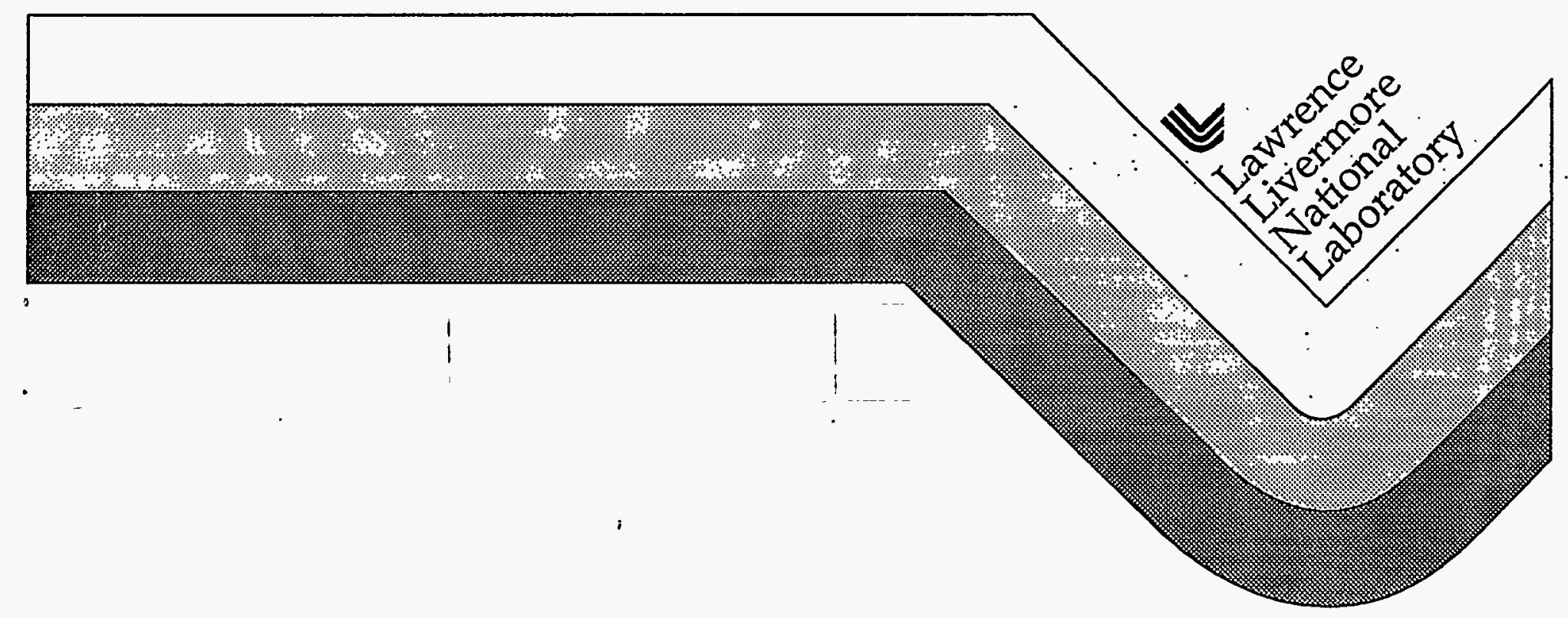




\section{DISCLAIMER}

This document was prepared as an account of work sponsored by an agency of the United States Government. Neither the United States Government nor the University of California nor any of their employees, makes any warranty, express or implied, or assumes any legal liability or responsibility for the accuracy, completeness, or usefulness of any information, apparatus, product, or process disclosed, or represents that its use would not infringe privately owned rights. Reference herein to any specific commercial product, process, or service by trade name, trademark, manufacturer, or otherwise, does not necessarily constitute or imply its endorsement, recommendation, or favoring by the United States Government or the University of California. The views and opinions of authors expressed herein do not necessarily state or reflect those of the United States Government or the University of California, and shall not be used for advertising or product endorsement purposes. 
DISCLAIMER

Portions of this document may be illegible in electronic image products. Images are produced from the best available original document. 


\section{Small Inertial Fusion Energy (IFE)}

Demonstration Reactors

William J. Hogan

Deputy ICF Program Leader

Lawrence Livermore National Laboratory

\section{Abstract}

ICF target design studies done for the Nova Upgrade have identified conditions under which the target ignition "cliff" is shifted to much lower drive energy albeit with the penalty that the gain achieved at a given drive eriergy is also smaller. These targets would repeatably produce the output and spectra of higher gain targets at low yield. They should, thus, allow building much smaller R\&D reactors with full thermonuclear effects. 'Demonstration reactors at the 1 to $100 \mathrm{MWe}$ level appear to be feasible with driver energies of 0.5 to $2.0 \mathrm{MJ}$ per pulse. These smaller, less expensive test and demonstration facilities should result in a lower IFE development cost. If the U. S. government builds a driver and target factory, it is also conceivable that commercial organizations could build their own scaled concepts of IFE reactors using the beams and targets supplied by the government's facilities.

\section{Introduction}

The U. S. National Energy Strategy ${ }^{1}$ describes a plan for developing Inertial Fusion Energy (IFE) by 2025. After ICF target ignition and gain is demonstrated and a reactor driver is selected, it envisions further engineering development of IFE in . three major facilities: a Laboratory Microfusion Facility
(LMF) for high gain target performance, an Engineering Test Facility (ETF) to prove high pulse rate capability, and a Demonstration Power Plant (DPP) to prove long term commercial performance. In contrast to that approach, this author proposes that one driver and one target factory be built to support all engineering development. Target experiments can best be carried out in a separate, single-shot chamber at the ETF. In high pulse rate tests, target yield and pulse rate can be independently selected so that all demonstrations can be accomplished at relatively low yield and fusion power. This approach dramatically lowers the cost of IFE development.

Assuming that Nova Upgrade is successfully built and operated, we should know by 2000 how well we can predict and control the location of the ignition cliff and the height of the gain curves. Figure 1 shows three such curves. : On the far right is the curve estimated for the hohlraum drive temperature of the LMF. Associated with this drive temperature is a certain capsule implosion velocity. The shaded region at the low energy end represents the uncertainty in the

location of the ignition cliff due to uncertainty in capsule surface finish. The other two gain curves show the effect of driving the capsule with higher hohlraum temperatures - the ignition threshold is lowered but the ultimate gain achievable is also reduced. Choosing a Nova Upgrade driver energy of 1$2 \mathrm{MJ}$ for targets whose gain prediction corresponds to

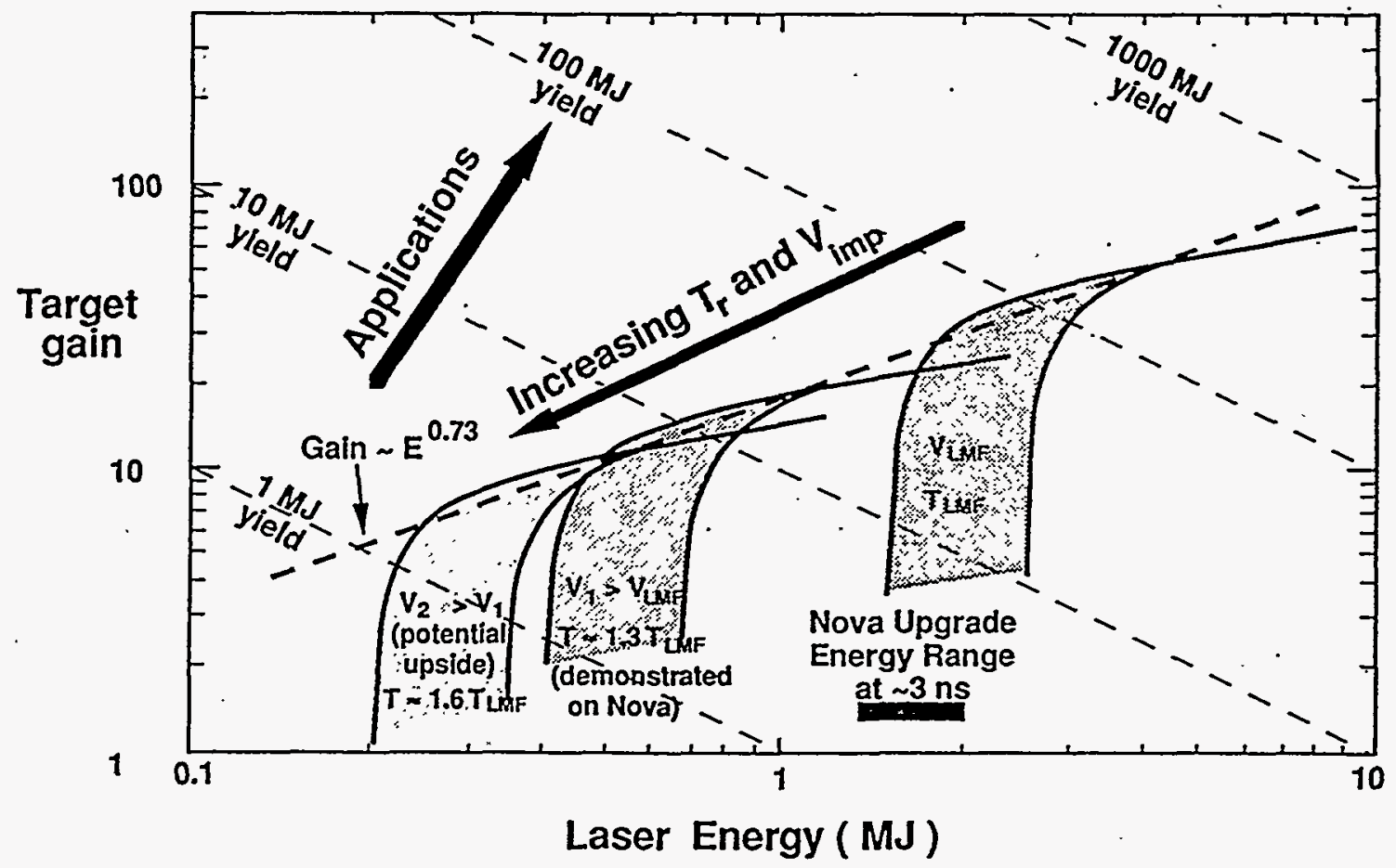

Fig. 1 Gain predictions for various hohlraum temperatures. The Nova Upgrade will reveal how well we can predict and control the location and height of the ignition "cliff"
- Work performed under the auspices of the U. S. Department of Energy by the Lawrence Livermore National Laboratory under Contract W-7405-ENG-48. 
the center curve will allow us to be far enough to the right of the uncertain ignition cliff to produce repeatable low yields with neutron and $X$-ray fluxes and spectra that are the same, at a properly scaled radius, as those from a high gain target. If a laser is selected for the ETF, these experiments will be sufficient to specify the required driver characteristics very well. If the heavy-ion driver is selected, the capsule physics results from Nova Upgrade will still be applicable but the driver will also have to demonstrate good driver/target coupling efficiency, and adequate uniformity and temporal precision of the $X$ rays on the capsule surface.

\section{Engineering Test Facility (ETF) goals}

The ETF program must include tests to demonstrate adequate $\eta \mathrm{G}(\geq 10)$ and pulse rates of $1-10$ $\mathrm{Hz}$ with the reactor driver. This can best be done in two separate experiment rooms of the ETF. Either lasers or heavy ions can support such separate experiment areas.

A low pulse-rate reaction chamber would be built to optimize target physics with the reactor driver and show that adequate $\eta \mathrm{G}$ can be obtained. Since, for economic viability ${ }^{2}$, gains of 30 to 100 will be needed with driver energies of 0.5 to $2.0 \mathrm{M}$, this chamber should be capable of yields up to $200 \mathrm{MJ}$ - far smaller than the maximum LMF desired yield of $1000 \mathrm{MJ}$ and, therefore, this chamber can be much less expensive. Such target experiments need take place only a few times per week. It is least costly to consider chamber designs that are very different from proposed reactor designs. No blanket or average thermal power heat removal system is needed. Neutron shielding can be outside the chamber because lifetime of the structure is not an issue. A dry wall design may be possible or, alternatively, a renewable wall design at smaller radius but with a renewing scheme that has a cycle time of only about one day is adequate. Design studies of such chambers ${ }^{3}$ suggest that they can be built for a few tens of millions of dollars.

Another major mission of the ETF is to show that pulse rates of $1-10 \mathrm{~Hz}$ can be obtained in a reactor, even with the difficult environment created when a target explodes. The reactor must extract the fusion energy and make tritium fuel for future targets in a safe, environmentally attractive and cost effective manner under these conditions. There are a large number of proposed reactor concepts ${ }^{4}$ for doing this. One function of the ETF will be to determine which of these concepts are feasible and which do the best job. For each concept we will want to know what is the maximum pulse rate, what is the failure rate as a function of the pulse rate, are there any effects that build up with many shots, are wall stresses as predicted, is the blanket working properly (tritium production, shock mitigation, energy deposition profiles), are there any wall erosion or other strength decreasing effects, are the driver/reactor interface systems working properly, is material activation as expected, and many other questions specific to each design. Doing many tests on many concepts at full reactor scale would obviously be prohibitively expensive. Some concepts are likely to have been eliminated in single-shot, wall-response tests performed at high flux facilities like Nova Upgrade well before the ETF is built. However, it is likely that many concepts will still be considered promising. Fortunately, it is possible to design scaled reactor experiments that would dramatically lower the cost of each test for this phase of ETF operation.

Ulimately, of course, it will be necessary to show that the fusion energy deposited can be used efficiently to power the driver and that tritium produced in the blanket and other target materials can be recovered to produce future targets. Completing the power and materials reprocessing cycles would be more expensive than the above tests. Even here, however, scaled tests might be done at a low power to reduce costs.

\section{ETF scaling}

Cost scaling for ETF experiments can only be done precisely in the context of the specific requirements for each test and is dependent on the concept tested. However, some generalizations are possible by considering the generic types of IFE reactor concepts under consideration.

For the ETF tests designed to determine the pulse rate achievable in a given reactor design, the power produced need not be used to generate electricity and the target fuel and other materials need not be recovered. Targets would be produced in a batch mode off line. Power could be purchased for the driver and other systems requiring it. Targets would be designed to give low yield while still providing the same output spectra. A target injection system would supply the targets to the chamber center at the specified pulse rate. The reactor costs would depend upon what concept is being tested. Let us suppose that three generic IFE reactor types are still under consideration - a dry wall reactor, a HYLIFE type with a thick internal blanket of liquid materials, and a Cascade type with a thick internal blanket of ceramic granule material. To understand how costs scale with yield I will make the simplifying assumption that all costs are proportional to the mass of a component.

In the dry wall case, the major costs of the reactor are those of the structural wall and the blanket. The structural wall must serve as the vacuum chamber and also contain the pressure generated by the fusion pulse. The external blanket performs the heat transfer and tritium production functions. In the scaled test the blanket must be the same thickness it is at full size to provide the same number of $14 \mathrm{MeV}$ neutron mean free paths. Thus, the blanket mass scales as $R_{b}{ }^{2}$, where $R_{b}$ is the blanket radius. The neutron flux scales as $Y / R_{b}{ }^{2}$. Thus, the energy deposited per unit mass could be constant, if $R_{b}$ is scaled as $Y^{1 / 2}$. Therefore, the blanket mass will scale as $\mathrm{Y}$, until the radius of the blanket was so small that the thin shell approximation no longer holds. The 
thermodynamics and tritium production performance of the blanket should, thus, scale precisely.

To hold a vacuum the thickness of the structural wall should be scaled linearly with the chamber radius, $R_{c}$. However, to contain the pressure generated in the explosion would require that the dynamic stress in the wall not exceed a specified limit. For a spherical chamber the wall stress is

$$
\sigma=P_{c} / 2 t
$$

where $P$ is the pressure and $t$ is the wall thickness. The pressure is just

$$
P=\frac{Y}{4 / 3 \pi R_{c}^{3}}
$$

where $\mathrm{Y}$ is the target yield. Thus to keep the wall stress constant as yield is scaled down the wall thickness should be scaled as

$$
t \dot{\alpha} \frac{Y}{R_{c}^{2}}
$$

To prevent wall vaporization, the wall radius should be scaled as $Y^{1 / 2}$. Thus, the wall thickness required is constant. The mass of the wall is

$$
M_{s} \propto \mathrm{tR}_{c}^{2} \alpha \mathrm{R}_{c}^{2} \propto Y
$$

Thus, the chamber and blanket costs both scale linearly with target yield.

In a HYLIFE type reactor the blanket is inside the structural wall. In this case the blanket also plays a role in the chamber dynamics determining pulse rate. The inside surface of the blanket is vaporized with each pulse and the vapor must be recondensed before the next pulse. The condensation time (the inverse of the maximum pulse rate) is proportional to the mass vaporized and inversely porportional to the surface area available for condensation. The latter should scale as $\mathbf{R}_{\mathbf{b}}{ }^{2}$ since the number of droplets scales thusly and the specific energy deposited in the liquid blanket by neutrons is constant (the particle size distribution of the resulting droplets is proportional to this quantity). If the thickness of material vaporized is held constant as we scale down, the mass vaporized should also scale as $R_{b}{ }^{2}$. If we scale the blanket radius as $Y^{1 / 2}$ to keep all fluxes constant, then all these dynamic properties should scale the same way and we will have a good test of both the blanket dynamics and blanket neutronics. Thus, in HYLIFE also the blanket mass and, therefore, cost scales directly with the yield.

- The scaling for the structural wall is somewhat different for HYLIFE or HYLIFE II, however. The structural wall serves as both vacuum barrier and explosion pressure containment, as before. However, if the vapor condensation time is comparable to or shorter than the structural response time due to the large surface area available, then the full dynamic pressure assumed in the dry wall case will not be felt by the structural wall and the thickness can be reduced.
In the limit, the wall thickness will scale directly with the chamber radius as it would for a simple pressure vessel. In this case the structural wall mass would scale as $R_{c}{ }^{3}$ rather than $R_{c}{ }^{2}$. The chamber radius would still scale as $Y^{1 / 2}$ since its scaling would be determined by the blanket scaling. Therefore, the chamber mass, and therefore, costs would scale as $Y 3 / 2$, reducing them even more than in the dry wall case.

In a Cascade type reactor there is an additional factor to consider. The structural wall and vacuum wall are separate. In this case the structural wall function is to keep the blanket in the proper position, and, therefore, its thickness will be determined by the mass per unit area of the blanket. Since this would be held constant for the same reasons as those described for HYLIFE, the reactor wall thickness would also be constant and the structural wall cost would scale linearly with yield. However, the vacuum vessel wall cost would scale as $Y^{3 / 2}$ as in the HYLIFE case.

\section{Minimum size ETF experiments to determine pulse rate}

The design yields in recent typical reactor studies range from $100 \mathrm{MJ}$ to $400 \mathrm{MJ}$ for the reactor types discussed above. To determine the minimum reliable target yield for reactor tests we must reexamine the target gain space in Figure 1. The center curve is the target design chosen for the ignition experiments on Nova Upgrade. At the 1-2 MJ planned driver energy, yields of $10-30 \mathrm{MJ}$ would be achieved - a factor of ten below reactor yields. If the higher temperatures of the left hand gain curve can be achieved, then reliable yields of only a few MJ might be obtained with drive energies of 0.4 to $1.0 \mathrm{MJ}$. Thus, the yield may be reliably reduced by a factor of $20-70$ - at least for laser drivers. Thus far, increasing hohlraum temperature is the only method. found for reducing drive energy requirements for ignition while preserving the hydrodynamic stability conditions presently believed to be necessary for high gain. This method appears to be satisfactory for laser drivers but it may prove difficult to utilize for ion beam drivers. It is, therefore, important to continue searching for other methods to reduce yield reliably for heavy ion targets.

Scaling the three reactor types discussed to sizes appropriate for yields of a few MJ produces the result shown in Table 1 . The radii are reduced by factors of 4.5 to 8 and costs are reduced by factors of 20 to 100 . Tests in these scaled reactors could start in the burst mode with, perhaps up to 1000 targets fired at rates from 0.01 to $10 \mathrm{~Hz}$. Thus, the required peak electrical power for the driver would range from $4 \mathrm{~kW}_{\mathrm{e}}$ to a few $\mathrm{MWe}$. Thermal power produced would range from 50 $\mathrm{kW}$ to a few $M W_{\mathrm{e}}$.

Minimum size ETF experiments for reactor: performance

Eventually one or more reactor concepts would have to be run with closed power and materials processing cycles. In this case we must consider both the gain curves and the power cycle in more detail. 
Table 1 Scaled high pulse rate test can result in costs reductions of factors of 28 to 80 for the major components

$\begin{array}{lccr} & \begin{array}{c}\text { Dry wall } \\ \text { reactor }\end{array} & \begin{array}{c}\text { HYLIFE-II } \\ \text { type reactor }\end{array} & \begin{array}{c}\text { Cascade } \\ \text { type }\end{array} \\ \text { Nominal reactor parameters } & & 1200 & 800 \\ \text { Power (MWe) } & 300 & 350 & 300 \\ \text { Yield (MJ) } & 160 & 8 & 5 \\ \text { Pulse rate (Hz) } & 5 & 5 & 5 \\ \text { Chamber radius (m) } & 8 & & \\ \text { Scaled high pulse rate tests } & & 20 & 17 \\ \text { Yield (MJ) } & 2 & 1.2 & 0.8-85 \\ \text { Chamber radius (m) } & 0.9 & 1.5-160 & \\ \text { Power (MWth) } & 0.1-10 & & 18 \\ \text { Cost reduction factor } & & 18 & 18 \\ \text { Blanket } & 80 & 74 & \gg 74 \\ \text { Structural wall } & 80 & \text { N/A } & \end{array}$

The gain curves shown in Fig. 1 maintained a constant driver/target coupling efficiency as hohraum temperature was increased. If the driver/target coupling efficiency is increased, then any given gain curve will move upward and to the left, along a constant yield curve. One objective of target experiments on Nova Upgrade (and the single-shot ETF chamber) after ignition is obtained will be to see if the driver/target coupling efficiency can be improved. A result of these experiments will be an upper bound for all possible gain curves set by realistic target physics constraints. In Fig. 2 are shown two possible such upper bounds for a laser driver, an optimistic one and a conservative one. The actual location of these limits is unknown at this time, of course, but two are shown in Fig. 2 for illustrative purposes. It is desireable to

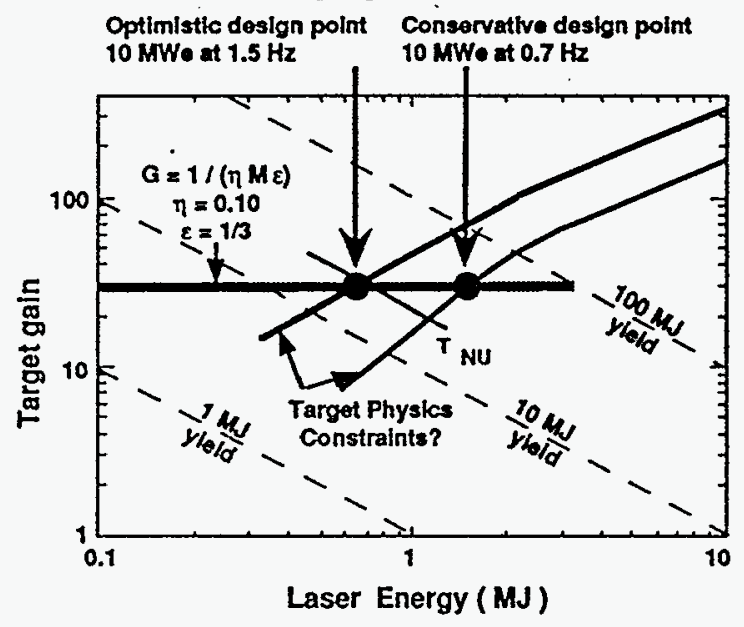

Fig. 2 Gains above 30 are required to produce enough energy to power a laser driver with an efficiency of $10 \%$.

operate a demonstration reactor as far to the left in this diagram as possible. The limit will be set by the desire to make enough electricity to run the driver in a closed loop. The recirculating power fraction in any IFE reactor is just $1 / \eta \mathrm{GM} \varepsilon$ where $\eta$ is driver efficiency, $G$ is target gain, $M$ is the reactor energy multiplier that accounts for tritium production reactions (typically 1.0

to 1.1), and $\varepsilon$ is the thermal-to-electric power conversion efficiency ${ }^{2}$. For an $\varepsilon$ of $1 / 3$, an $M$ of 1.0 and an $\eta$ of 0.1 , the minimum gain necessary for a recirculating power fraction of 1 is $G=30$ (the horizontal line in Fig. 2). The corresponding target yields would be 20 and $40 \mathrm{MJ}$ for the optimistic and conservative gain limits respectively. With a pulse rate of about $1 \mathrm{HZ}$, a reactor that runs itself can be tested at a power level of only $10 \mathrm{MW}_{\mathrm{e}}$. Gradually the pulse rate could be increased to the desired range and the power would still be only 10 to $100 \mathrm{MWe}_{\mathrm{e}}$. The power range over which this demonstration reactor could operate would be determined entirely by the thermal and electrical power handling equipment used, not by the conditions necessary for thermonuclear burn. Thus, commercial power companies could choose to do very low-power, low-cost experiments in order to evaluate and get used to IFE power reactor technology.

Figure 3 shown similar gain limit curves and possible low-power design points for heavy-ion-driven targets and reactors. In this case a driver efficiency of $25 \%$ is assumed and, therefore, the minimum gain for

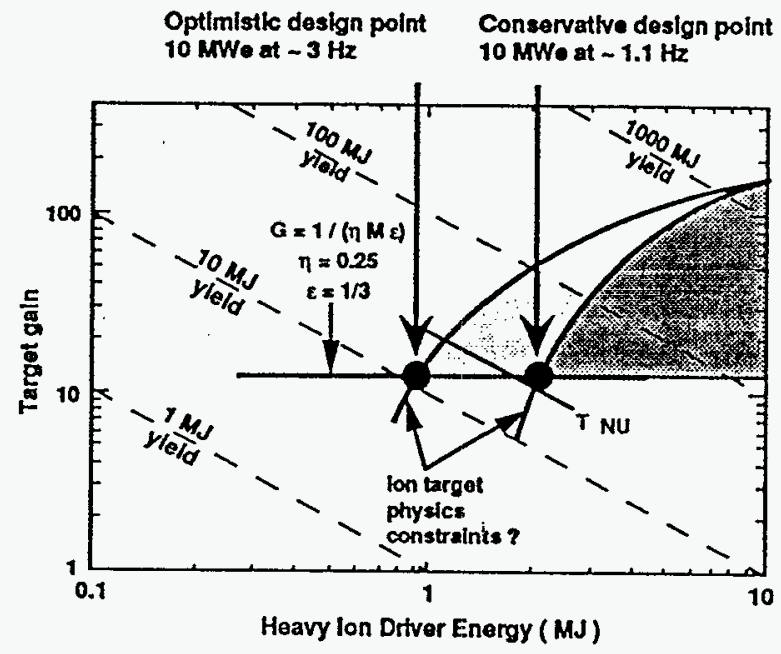

Fig. 3 Gains greater than 12 will provide enough power to run a heavy ion driven reactor with an efficiency of $25 \%$. 
self sufficiency in power is $G=12$. The yields for the optimistic and conservative curves are 11 and $25 \mathrm{MJ}$ respectively. Again any pulse rate can be chosen depending on the power handling equipment installed, and, therefore, the facility power can be quite low.

Another point to notice in the above development scenario is that the target yields and driver energies used in the initial reactor demonstrations are just those expected in the Nova. Upgrade experiments. Thus, if those experiments are successful, burst mode and small-scale, complete power plant trials could occur at the beginning of ETF operation, in parallel with (or even earlier than, if the driver is built in modules starting at, say, $1 \mathrm{MJ}$ ) experiments in a larger, single-shot chamber to optimize target/driver performance at higher gains.

\section{Conclusions}

Ultimately, of course, a prototype power plant will be built at a power level appropriate for planned future commercial operations. This could use the same ETF/DPP driver or a new ore tailored to the plant size and with less experimental flexibility than the ETF driver. With the experience and data gained from a number of small demonstration reactors, and from the operation of the ETF/DPP driver and target factory, it is quite likely that a variety of plant sizes options will be available at that time.

The scenario explored here is a relatively lowcost development program for fusion energy, which encourages technology transfer to industry at an early stage. If the government builds an ETF driver, target factory, a single-shot experiment area, and a burst mode facility, commercial companies may be interested in building their own small demonstration reactors which would be supported by the government facilities. The fact that the ETF and any number of DPP's could be supported by the same driver and target factory means that the incremental cost of trying many alternatives is small. The fact that IFE demonstration reactors can test all relevant parameters at low power means that IFE has no extremely high-cost (multibillion dollar) development facility to build in order to demonstrate engineering feasibility - i.e. there is no large development "hurdle" to surmount. We can, indeed, start small and work our way larger as the results justify. The result of this approach may produce competitive IFE power plant designs at a few hundred to a few thousand megawatts.

\section{References}

1. National Energy Strategy, First Edition 1991/1992, U. S. Department of Energy, Washington, DC, February, 1991.

2. Hogan, W. J. and Meier, W. R., "Economic Requirements for Competitive Laser Fusion Power Production", 11th Symposium of Fusion Engineering (and UCRL-92559), Austin, Texas, November, 1985.

3. Laboratory Microfusion Facility Phase II Study, U. S. Department of Energy, to bo published.

4. W. J. Hogan and G. L. Kulcinski, "Advances in ICF Power Reactor Design, Fusion Technology, Vol. 8, July, 1985. This paper found 47 reactor concepts at that time. This author has found at least 6 more since that date. 